\title{
Examining the interfaces to e-journal articles: what do users expect?
}

Conference or Workshop Item

Accepted Version

Dyson, M. C. and Jennings, E. M. (2014) Examining the interfaces to e-journal articles: what do users expect? In: DUXU 2014, June 2014, Creta Maris, Heraklion, Crete, Greece, pp. 164-173. Available at http://centaur.reading.ac.uk/38642/

It is advisable to refer to the publisher's version if you intend to cite from the work. See Guidance on citing.

Published version at: http://link.springer.com/chapter/10.1007/978-3-319-07635-5_17

All outputs in CentAUR are protected by Intellectual Property Rights law, including copyright law. Copyright and IPR is retained by the creators or other copyright holders. Terms and conditions for use of this material are defined in the End User Agreement. 


\section{CentAUR}

Central Archive at the University of Reading

Reading's research outputs online 


\title{
Examining the interfaces to e-journal articles: what do users expect?
}

\author{
Mary C Dyson and Elizabeth M Jennings \\ Department of Typography \& Graphic Communication, University of Reading, UK \\ M.C.Dyson@reading.ac.uk,E.M.Jennings@student.reading.ac.uk
}

\begin{abstract}
Researchers are increasingly relying on e-journals to access literature within their fields. The design of the interfaces to these journals is determined by the individual host or publisher and there appears to be little standardization. This exploratory study samples a set of sixteen home screens of e-journals from different disciplines and identifies common features across the set. The particular wording used to identify the features and their locations are recorded. An online survey of e-journal readers investigates where users would normally expect to locate features when first accessing a journal article. Comparison of observed and expected locations confirms inconsistencies across interfaces in terminology and locations. Mental models of the interface design do not appear to be well developed. A move toward standardization, based on some existing conventions, is desirable.
\end{abstract}

Keywords: conventions; standardization; screen layout;

\section{Introduction}

A primary means for researchers to gain access to academic knowledge is through ejournals. In the UK, studies adopting a fairly general perspective have looked at how academic libraries support research and teaching; how reading patterns differ across articles and books; how researchers have responded to the convenience of access to ejournals; and how this access has influenced the quantity and quality of research outcomes, e.g. [1-2]. Looking in more detail at researchers' search behaviors on publisher e-journal platforms, preferences have been found for particular routes to journal articles, e.g. gateway or third-party sites [1].

Library and Information Science approaches identify and analyze system functionality and users' search strategies, but the design of user interfaces does not fall within their scope. With the plethora of routes to journal articles, i.e. through gateways, hosts, via databases or discovery services, a researcher may encounter many different interfaces before reaching the article itself. Although functionality may be similar, publishers use different terms, and their screen layouts vary. In particular, a researcher working in an inter- or multi-disciplinary field, such as HCI or Information Design, researches topics that cross many subjects which therefore require interaction with a wide range of resources. Typically researchers wish to locate various items or tools,

adfa, p. 1, 2011.

(C) Springer-Verlag Berlin Heidelberg 2011 
e.g. author guidelines, citation tools, past issues of a journal. Tools for interacting with the content may go beyond navigation to offer image manipulation, e.g. Elsevier's Protein Viewer.

\subsection{Potential problems}

Whilst the current situation provides greater flexibility than previously, and the affordances of the interfaces are increased, the different layouts and manipulation tools may introduce inefficiencies and frustration. General Internet users have mental models for the location of various web objects, e.g. home link, navigation areas [3-4]. Violating visual conventions can leave users disoriented and hinder their performance [5]. However, if such conventions have not yet developed for e-journal articles, mental models are unlikely to exist or may be inaccurate, given the diversity of interface designs.

Current technology offers many data visualization tools that may be embedded as interactive image features. This great variety of tools and associated lack of standardization may also provide users with a more complex environment in which to diagnose and recover from technical problems. Users' inability to complete tasks frequently leads to frustration, as established by [6-8].

\section{Methods of investigation}

This exploratory study develops a systematic description of a number of interface features against which users' expectations can be compared by:

- Analysing the interface designs of e-journals to determine whether they are consistent in the naming and location of specific items

- Collecting data on researchers' expectations regarding the location of common features

- Pilot work on identifying and analyzing examples of interactive image features

\subsection{Analysis of features in e-journal interfaces}

Sixteen examples of the home screens of e-journals were selected, which aimed to cover different publishers (e.g. Elsevier, Wiley, ACM, Taylor \& Francis); and disciplines (e.g. HCI, Neuroscience, Design history, Chemistry, Psychology). Screen shots were overlaid with a grid of 2 inch squares to delineate areas of the screen (Fig. 1 and Fig. 2).

Features that recur on most pages were identified and their location within one or more of the cells recorded, along with the particular wording used to identify that feature. From this list of sixteen, seven features were selected for the user survey based on those which appeared to be present in most of the sample, and those that were considered relevant to users' typical activities. The wording on the survey took account of the different descriptors, i.e. alternatives were indicated. The features were 
About this journal/Aims and scope; Email/article alerts; Guide or instructions for authors/submit manuscript; Help or Contact us; Login/Sign in; Name of journal probably including thumbnail (small image) of cover; Search the journal.
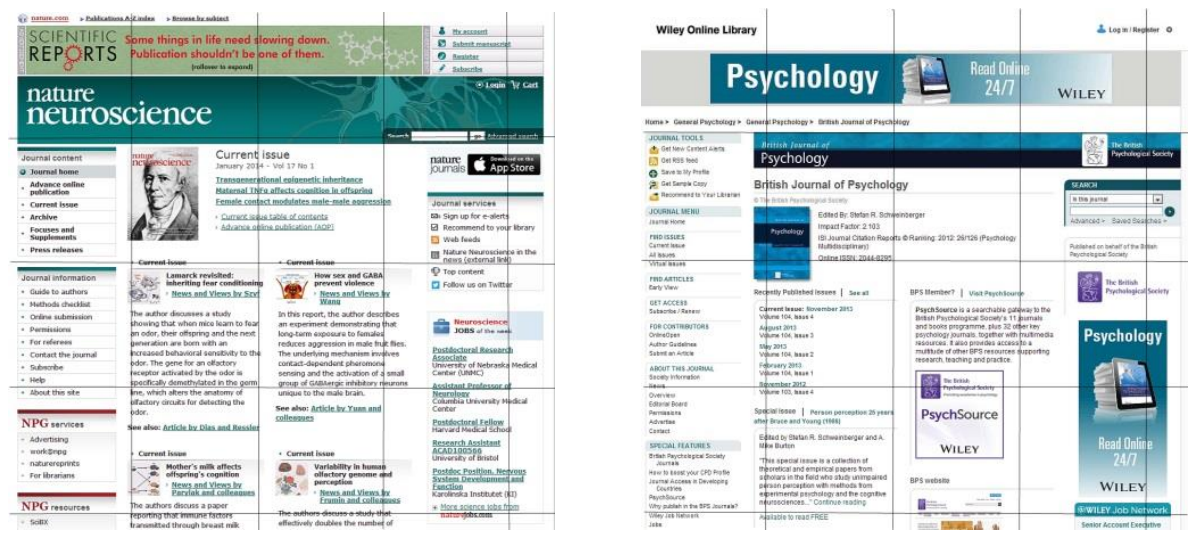

Fig. 1 and 2. Examples screens with grids to divide area into 16 cells

\subsection{Survey of researchers' expectations}

An online survey was distributed to academics, research staff, and postgraduate students within the University of Reading, UK, and 53 responses were received. This asked respondents to indicate where they would normally expect to locate features when first accessing a journal article. They were provided with a 4 x 4 grid with numbered cells to locate items (Fig. 3) and could propose more than one cell per item, or more than one area. This was considered necessary to allow for respondents' uncertainty over precise locations. These questions were followed by a question on locating the Export citation feature, having accessed a journal article. For this question, a modified grid indicated possible areas (Fig. 4)

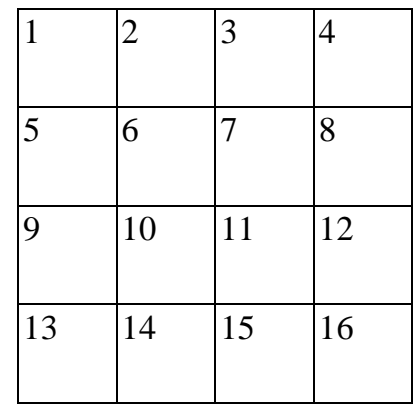

Fig. 3. Grid indicating possible locations of features

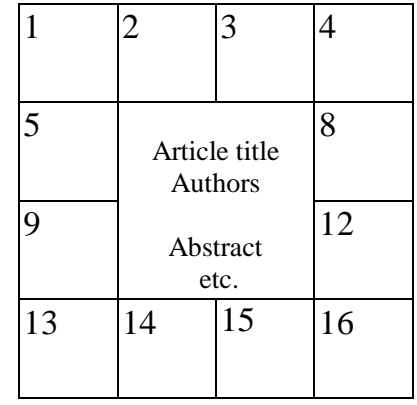

Fig. 4. Grid representing first page of journal article, to indicate location of Export citation feature 


\subsection{Examples of interactive image features}

Two interactive image features were identified within journal articles: one employing Elsevier's Java-based Protein Viewer; ${ }^{1}$ the second embedding a Google Earth layer to provide supplementary geospatial data to users. ${ }^{2}$

\section{Results}

The survey asked which journals respondents access most frequently, to gain an idea of the disciplines covered. Science, Social Sciences, Arts and Humanities were represented, which provides a reasonable match with the selection of examples included in the analysis (see 2.1). About two thirds of respondents reported that they typically use a desktop computer to locate articles, and the remaining third, a laptop, rather than tables or phones. The grid could therefore be considered a reasonable representation of a typical home screen.

\subsection{Observed locations}

The location of About this journal is heavily dependent on the publisher, and can fall in any one of 7 cells, mainly in the top area of the page. The other features are spread across fewer distinct locations. For example Email or article alerts are in the top right ( 8 out of 15 instances) $)^{3}$ or the middle left (4/15); Guide for authors tends to be positioned on the right around the middle (7/14), but a few publishers use the middle left (4/14). The features which are more generic, i.e. there are parallels on other web sites, are clustered in one area of the screen: Login across the top, mainly on the right ( 7 of the 14 at the top are on the right); Name of journal, top left (10/16); Search the journal, top right (8/15) or top left (4/15). Help or Contact us is mainly in the top right $(8 / 16)$.

\subsection{Expected locations}

Figs 5 to 11 summarize the locations indicated by respondents for each feature, with numbers indicating frequency of responses, ${ }^{4}$ and darker shading reflecting greater agreement. $^{5}$

\footnotetext{
1 http://dx.doi.org/10.1016/j.jmb.3009.11.045

http://dx.doi.org/10.1016/j.tecto.2005.08.029

3 Although 16 journals were included in the analysis, some did not include all of the features. The total number of possible locations may therefore be less than 16 .

4 Data is reported as frequencies, rather than converting to percentages, as the frequencies enable a comparison of the strength of responses across features.

5 Shading was applied to bands of 5 responses with 36-40 shaded black.
}

adfa, p. 4, 2011.

(C) Springer-Verlag Berlin Heidelberg 2011 
The Export citation feature (Fig. 12) was recalled as appearing in various locations on screen. Although this feature was not included in the analysis described above, the personal frustration of the first author was the motivation for including this feature. This experience was echoed by one respondent commenting on e-journal interfaces: 'I wish they were more standardised. The hardest thing to find is the citation manager link!'

Other general comments reinforced the desire for standardization: 'It would be useful if they all have a standard layout, that is, where search article, guidelines to authors, etc. are located'. One respondent commented on who might be responsible for the problem: 'When the link to each task is not located where I expected it to be I tend to question the designer of the interface or the publisher.' This opinion runs counter to [9] who suggests that when users of information design products have difficulties, they may attribute them to their own ineptitude. This divergence may be explained by the particular user group, i.e. academics may tend not to blame themselves. There was also a negative perception of the overall interface design: 'websites are usually very cluttered'.

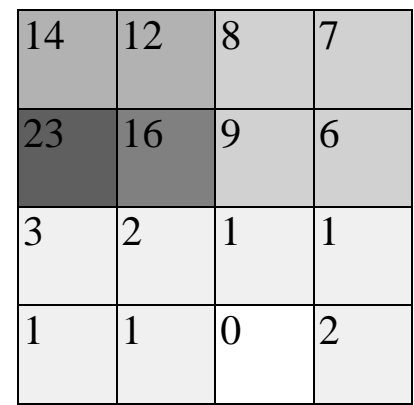

Fig. 5. About this journal

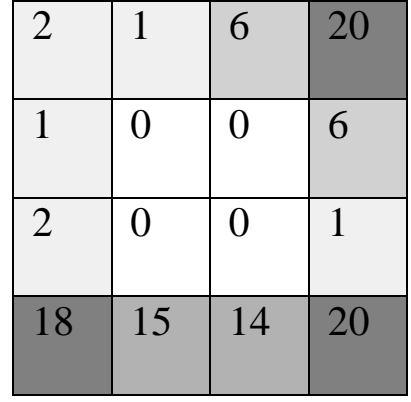

Fig. 8. Help or Contact us

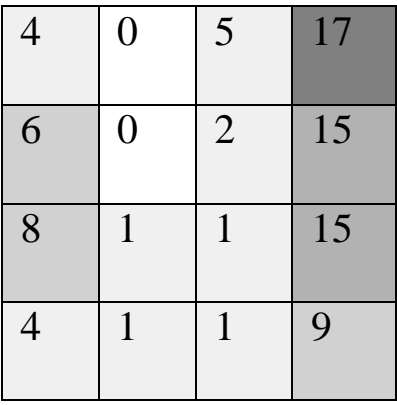

Fig. 6. Email alerts

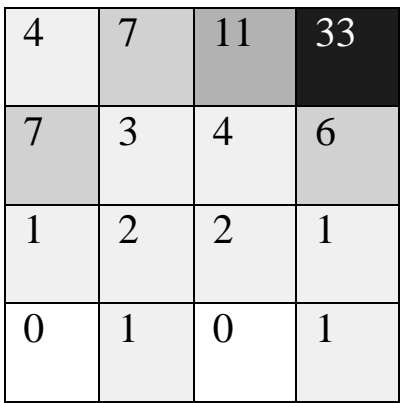

Fig. 9. Login/sign in

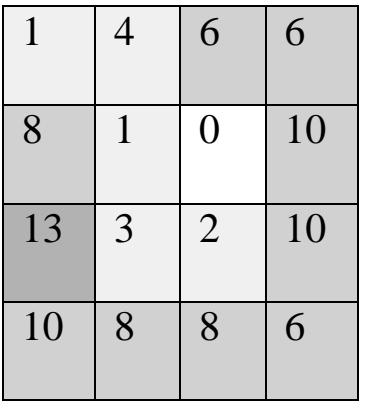

Fig. 7. Guide for authors

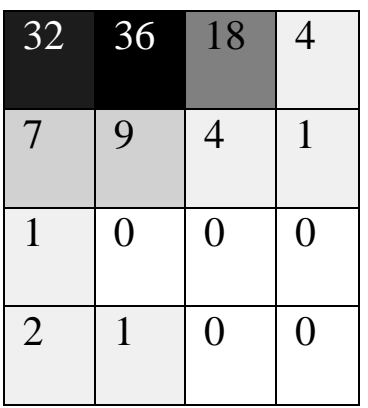

Fig. 10. Name of journal 


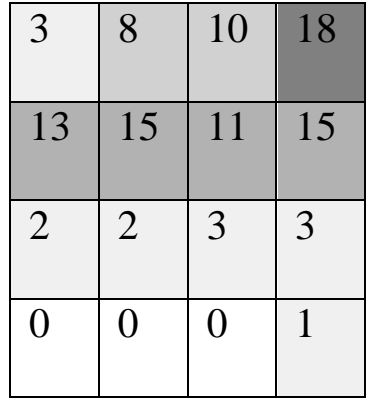

Fig. 11. Search the journal

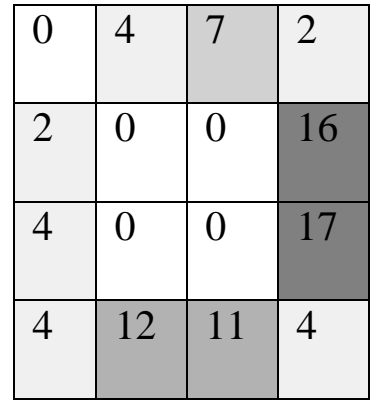

Fig. 12. Export citation

\subsection{Comparison of expected and observed locations}

The most consistent responses are the expected locations of Login/sign in and Name of journal. Sites which require logins commonly place these in the top right and users expect this location [4]; e-journals are generally adopting this convention. The journal name is commonly located top left, as respondents suggest. However, a few are positioned slightly lower down, as the name of the publisher or the host takes the top left position (Fig. 13).

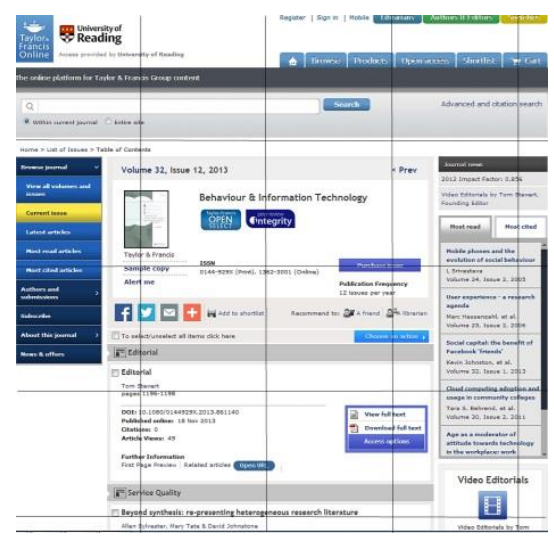

Fig. 13. Journal name is located lower as publisher's name occurs first

Help or Contact us is slightly less consistent, reflecting a spread of expected locations across the bottom of the screen, rather than on one side, and a separate location at the top right. This split was also found by [4] for their help link. The top right is the most frequent observed location, but various other positions were recorded. The lack of standardization and ambiguity in respondents' locations may be due to conflation of 
similar, though not necessarily identical, functions. In the analysis stage, the wording recorded included help, contact us, support, FAQ. To simplify, and allow for different terms for the same feature, the survey used the descriptors Help or Contact us.

The Guide for authors/submit manuscript shows the most variation among participants as to its expected location, even though it tends to be found in similar locations across publishers. This might be explained by the frequency with which users access this feature, in comparison with the others. Its location may be more difficult to recall if it has not been incorporated into user's mental models.

The diversity of responses in locating Email or article alerts may also be due to the infrequent use of this feature. Once alerts are set up using this tool, there is no need to repeat the process. Nevertheless, there is some association between the observed locations (top right and middle left) and expectations, although respondents suggest more use of the right side than was found in the sample that was analyzed.

An example of the reverse situation is About this journal, where observed locations are distributed across various parts of the screen but respondents are more consistent in their responses. Respondents generally expected to find this feature in the top area of the screen, more likely on the left, and below the journal name. This seems to be a logical position given the introductory nature of this feature. Users expect to find About us in a similar area of the screen in online shops, news portals, and company web pages [4].

The search bar can be quite wide (Fig. 12) and therefore extend over a number of cells. This is reflected in both the observed and expected locations. However, respondents positioned the feature at both the top and lower down. The lower positions may be taking account of the location of other features, such as the journal name and login, above the search tool.

\subsection{Analysis of interactive image features}

We were unable to load the Jmol-based Protein Viewer in any web browsers available to us, which illustrated that security and other settings can impede a user's ability to access applets integrated into web publications. In contrast, the Google Earth layer functioned seamlessly and provided a more satisfactory user experience. In the next stage of our research, we intend to explore how a user's frustrating experience with one interactive image feature may influence a second, subsequent experience with another image feature.

\section{Conclusions}

The exploratory analysis and survey suggest that:

- Features do not share common locations across publishers' interfaces

- Where there may be only two distinct locations, these are on different sides of the screen

- There is variation in terminology 
- E-journal interfaces are adopting some visual conventions from other types of web sites to locate more generic features that are shared among sites

Many users may not yet have developed a coherent mental model of the overall layout because:

- Some features are rarely used

- Inconsistency among regularly used interfaces may inhibit transfer from one journal to another

- The interfaces appear cluttered

Limitations and recommendations:

- The small scale nature of the study and the relatively crude measurement tools (i.e. coarse grids) suggest caution in deriving any firm conclusions

- There may be some constraints placed on the overall design in order to fit with the brand or template used by the publisher or host

- A move towards standardization of the terminology and location of the most common features, drawing on existing conventions where possible, would ease frustrations in interacting with the interfaces

\section{References}

1. Research Information Network: E-journals: their use, value and impact (2011) http://www.rin.ac.uk/our-work/communicating-and-disseminating-research/e-journalstheir-use-value-and-impact [6 February 2014]

2. Tenopir, C.,Volentine, R.: UK scholarly reading and the value of library resources: Summary results of the study conducted spring 2011. Knoxville, TN: JISC Collections Center for Information and Communication Studies, University of Tennessee (2012)

3. Shaikh, A. D., Lenz, K.: Where's the search? Re-examining user expectations of web objects. Usability News, 8(1) (2006) http://usabilitynews.org/wheres-the-search-reexamining-user-expectations-of-web-objects/ [6 February 2014]

4. Roth, S. P., Schmutz, P., Pauwels, S. L., Bargas-Avila, J. A., Opwis, K.: Mental models for web objects: Where do users expect to find the most frequent objects in online shops, news portals, and company web pages? Interacting with Computers, 22(2), 140-152 (2010)

5. Santa-Maria, L., Dyson, M.C.: The effect of violating visual conventions of a website on user performance and disorientation. How bad can it be? SIGDOC'08, 47-54 (2008)

6. Ceaparu, I., Lazar, J., Bessiere, K., Robinson, J., Shneiderman, B.: Determining causes and severity of end-user frustration. International Journal of Human-Computer Interaction, 17(3), 333-335 (2004)

7. Hertzum, M. Frustration: A common user experience. In: Hertzum, M., Hansen, M. (eds.) DHRS 2010: Proceedings of the Tenth Danish Human-Computer Interaction Research Symposium. Computer Science Research Report 132, Roskilde University, Roskilde, Denmark (2010)

8. Lazar, J., Jones, A., Shneiderman, B.: Workplace user frustration with computers: An exploratory investigation of the causes and severity. Behaviour \& Information Technology, 25(3), 239-251 (2006) 
9. Adams, A.: Usability testing in information design. In Zwaga, H. J. G., Boersema, T., Hoonhout, H. C. M. (eds.) Visual information for everyday use, pp. 3-20. Taylor \& Francis, London (1999) 